\title{
Risk of postoperative nausea and vomiting in hip and knee arthroplasty: a prospective cohort study after spinal anaesthesia including intrathecal morphine
}

\author{
Antonio Moraitis ${ }^{1 *}$ (D) Magnus Hultin ${ }^{2}$ (D) and Jakob Walldén ${ }^{1}$ (D)
}

\begin{abstract}
Background: The overall risk of postoperative nausea and vomiting after general anaesthesia is approximately 30\% even with prophylactic medications. Studies exploring the risk after regional anaesthesia including intrathecal morphine are limited but indicate that intrathecal morphine is highly emetogenic and is additive to the PONV risk associated with other forms of anaesthesia. The aim of this observational study was to investigate the risk of PONV after spinal blockade combined with intrathecal morphine and to explore associations with patient and perioperative factors, including given PONV-prophylaxis. We hypothesized that a large number of patients in a clinical setting receive less prophylaxis than the recommendations in guidelines (suboptimal prophylaxis), leading to a higher risk for PONV compared to those receiving adequate PONV prophylaxis.
\end{abstract}

Methods: The study was conducted as a prospective observational cohort study regarding PONV in patients undergoing hip/knee replacement under spinal anaesthesia including intrathecal morphine. Patients were included at a county hospital in Sweden during April-November $2013(n=59)$ and September 2014-June $2015(n=40)$. One hundred eight patients entered the study with 99 patients analysed in the final cohort. Patients were followed the first three postoperative days with a questionnaire regarding PONV and peri- and postoperative data was collected. PONV risk is presented as the proportion of patients (\%) with PONV and was related to the level of perioperative PONV-prophylaxis (suboptimal/optimal). Univariate analysis was used to analyse factors associated with PONV.

Results: Forty-six patients (46\%) experienced PONV during the 3-day study period whereof 36 patients (36\%) until noon the first day after the procedure. 19/27 patients (70\%) that received suboptimal PONV-prophylaxis experienced PONV compared to 27/72 (38\%) that received optimal PONV-prophylaxis $(p=0.015)$. Further, female gender and/or a history of motion sickness were associated with an increased PONV-risk.

Conclusions: There was a high risk for PONV after spinal anaesthesia including morphine. PONV risk was associated with the level of prophylaxis and with known risk factors for PONV. Our findings suggest that a more liberal use of PONV prophylaxis might be motivated.

Keywords: Postoperative nausea and vomiting, Injections, Spinal, Prevention \& Control, Arthroplasty, Morphine

\footnotetext{
* Correspondence: antonio.moraitis@umu.se

${ }^{1}$ Department of Surgical and Perioperative Sciences, Anaesthesiology and Intensive Care Medicine (Sundsvall), Umeå University, Sundsvall, Sweden Full list of author information is available at the end of the article
}

(c) The Author(s). 2020 Open Access This article is licensed under a Creative Commons Attribution 4.0 International License, which permits use, sharing, adaptation, distribution and reproduction in any medium or format, as long as you give appropriate credit to the original author(s) and the source, provide a link to the Creative Commons licence, and indicate if changes were made. The images or other third party material in this article are included in the article's Creative Commons licence, unless indicated otherwise in a credit line to the material. If material is not included in the article's Creative Commons licence and your intended use is not permitted by statutory regulation or exceeds the permitted use, you will need to obtain permission directly from the copyright holder. To view a copy of this licence, visit http://creativecommons.org/licenses/by/4.0/ The Creative Commons Public Domain Dedication waiver (http://creativecommons.org/publicdomain/zero/1.0/) applies to the data made available in this article, unless otherwise stated in a credit line to the data. 


\section{Background}

The overall risk of postoperative nausea and vomiting (PONV) after general anaesthesia is reported to be approximately 30\% even with prophylactic medications, but studies exploring the risk after regional anaesthesia including intrathecal morphine are limited [1, 2]. Hip and knee arthroplasty can be performed under regional anaesthesia using a spinal blockade, and postoperative pain can be reduced by adding intrathecal morphine [3, 4]. However, this method might be associated with a high risk of PONV $[5,6]$.

In Apfel's model for assessing PONV risk, developed for general anaesthesia, significant risk factors are being female, non-smoker, having prior history of PONV and/or motion sickness, need of opioids for postoperative analgesia. If all factors are present, the risk of PONV can be as high as 80\% [7].

Apfel's risk score is often used for procedures under regional anaesthesia and prophylaxis given according to guidelines. Commonly used prophylactic drugs acting via different pharmacological targets are corticosteroids (anti-inflammatory), ondansetron (5-hydroxytriptamine $3\left(5-\mathrm{HT}_{3}\right)$ receptor antagonist) and droperidol (dopamine $\mathrm{D}_{2}$ receptor antagonist), which are equally effective and each independently reduce PONV with approximately 25\% [8]. Despite increased awareness and the introduction of new antiemetics, PONV is still a problem in the perioperative period. Risk stratification and a multimodal approach are key elements but are only effective if implemented and complied with, especially in high-risk patients [9-12]. Screening for PONV and a multimodal prophylaxis and treatment have a moderate evidence level and a strong recommendation grade [13].

The aim of this observational study was to investigate the risk of PONV in spinal blockade combined with intrathecal morphine and to explore factors associated with PONV with a focus on if the level of given PONV prophylaxis adhered to the guidelines. We hypothesized that a large proportion of patients receive less prophylaxis than recommended in a clinical setting, leading to a higher risk for PONV compared to those receiving adequate PONV prophylaxis.

\section{Methods}

\section{Study design}

The study cohort was part of a prospective observational cohort study regarding PONV. After obtaining written informed consent from the patients, data were collected from patient medical charts and through a standardized form with questions regarding PONV. The study was approved by the Regional Ethics Committee in Umeå, University Campus, Umeå, Sweden, on May 8, 2012 (Chairperson A. Iacobaeus, Dnr 2012/146-31 M).

\section{Study cohort}

Our study cohort consisted of patients at Sundsvall Hospital, Sweden, undergoing hip/knee replacement under spinal anaesthesia including intrathecal morphine. Inclusion criteria were, besides the criteria for the cohort, age $\geq 18$ years and being able to participate. Due to research resources, the inclusion was performed during two periods, April-November $2013(n=59)$ and September 2014-June $2015(n=40)$.

\section{Anaesthesia and PONV prophylaxis}

The choice of anaesthesia, PONV prophylaxis and pain management was based on clinical routines and at the discretion of the attending anaesthesiologist. At the time of the study, the clinical routine for hip and knee arthroplasty was spinal anaesthesia with bupivacaine 15-20 $\mathrm{mg}$, morphine $0.12 \mathrm{mg}$ and clonidine $30 \mu \mathrm{g}$. PONV prophylaxis during anaesthesia were given according to local guidelines which stipulates that patients should be given a number of PONV prophylaxes equal to one less than the value of each patients Apfel-score. Drugs used for PONV prophylaxis were betamethasone $4 \mathrm{mg}$, ondansetron $4 \mathrm{mg}$, and droperidol $0.5-1 \mathrm{mg}$ intravenously with a priority in that same order. Further, paracetamol $(1 \mathrm{~g} \times 4)$ and an oral depot opioid (oxycodone $10-20 \mathrm{mg} /$ day) was given as base analgesics. Some patients also received a cox- 2 inhibitor (etoricoxib 90-120 $\mathrm{mg}$ ) in the premedication and some patients received gabapentin (600-900 mg/day) postoperatively for up to 7 days. As rescue analgesic, either intravenous morphine or peroral oxycodone were used. For all patients, an enhanced recovery pathway was used including early nutrition and mobilisation.

\section{Patient classification according to PONV risk and given prophylaxis}

The simplified PONV risk score, developed by Apfel et al., was used to calculate the predicted the PONV risk [7]. Factors included in the model were female gender, non-smoking status, history of previous PONV and/or motion sickness, and use of postoperative opioids yielding a risk score of maximum 4. According to published guidelines, the optimal number of PONV prophylaxis to be given is related to the risk score [8]. To classify if patients had received PONV-prophylaxis according to our local guidelines, we (ourselves) defined optimal prophylaxis as the number of PONV prophylaxes needed being one less than the value of the risk score. When the number of prophylactic drugs given were less than optimal prophylaxis, patients were classified as having received suboptimal prophylaxis. Thus, suboptimal prophylaxis indicates that patients receives less PONV-prophylaxis than recommended. Our model is a simplification of the consensus guidelines published in 2014 [8], with the main difference that with four risk factors, where the guidelines states two or more interventions, we considered three interventions as optimal. 


\section{Data collection}

Preoperatively, patients were asked questions regarding risk factors for PONV. Postoperatively, patients answered a questionnaire with standardized questions regarding PONV at 2, 4, and $6 \mathrm{~h}$ after arrival at the recovery unit and at noon on postoperative days 1-3. The PONV questions were based on a validated scale for assessing PONV [14]. With the patient form, data regarding vomiting, retching, and nausea were obtained for each evaluation period, as well as the frequency of nausea [sometimes /often /most of the time /all the time] and if any rescue medications were given. Patients were also instructed to estimate any pain and to specify if any extra pain-relieving medicine had been taken. Further study data were obtained from the patients' medical records and the perioperative charts.

\section{Primary outcome variables}

PONV was defined as the presence of nausea and/or vomiting.

- Cumulative number of patients (\%) with PONV over the observation intervals.

- Number of patients (\%) with PONV during the postoperative intervals $0-2 \mathrm{~h}$ (hours), 2-4 h, 4-6 h, 6 h - Day 1, Day 1 - Day 2 and Day 2-Day 3.

- Number of patients with suboptimal or optimal PONV-prophylaxis.

- Number of patients (\%) with PONV in relation level of prophylaxis (suboptimal/optimal).

\section{Secondary outcome variables}

Patient and perioperative factors associated with PONV risk.

\section{Statistical methods}

PONV risk is presented as the proportion of patients (\%) with PONV, and a corresponding 95\% confidence interval was calculated for PONV risk using the method recommended by Newcombe and Altman [15].

To explore factors associated with PONV risk, we performed univariate analysis on dichotomized data with Pearson's chi-squared test and calculated odds ratios (ORs) with the corresponding 95\% confidence intervals.

Data were entered in spreadsheets (Excel, Microsoft, Redmond, Washington, USA), and statistical analysis was performed with SPSS (IBM Corp. Released 2016, IBM SPSS statistics for Mac, Version 24, Armonk, New York, USA). Bar charts were created with MATLAB (Release 2018b, The MathWorks, Inc., Natick, Massachusetts, USA).

We did not perform any power calculation, although we considered the final study cohort of 99 patients to be an appropriate size for an observational study of a standardized procedure.

\section{Results}

\section{Patient characteristics}

Preoperatively, 109 patients were screened and asked for participation in the study, with 108 patients included. Seven patients did not receive spinal morphine and two patients had not answered any of the questions in the questionnaire, thus a final cohort of 99 patients were analysed.

The patients had a median age of 67 years (range 38-87 years), and 57\% were female. Seventy-eight patients (79\%) underwent hip arthroplasty and 21 (21\%) underwent knee arthroplasty. The median dose of intrathecal morphine was $0.12 \mathrm{mg}$ (range $0.08-0.20$ ), and all patients received $30 \mu \mathrm{g}$ intrathecal clonidine. Fifty-five patients (55\%) had a high predicted risk for PONV (Apfel-score 3 or 4). For further patient characteristics see Table 1.

\section{PONV prophylaxis}

Ninety-four patients (94\%) received betamethasone, 53 (54\%) received ondansetron, and 20 (20\%) received droperidol as PONV prophylaxes. Of those given only one prophylactic drug, 42 patients received betamethasone and 3 received ondansetron. The 31 patients given two prophylaxes all received betamethasone and ondansetron.

Twenty-seven patients $(27 \%)$ received suboptimal prophylaxis in relation to their PONV risk score, and there was a significant difference between women and men in given suboptimal prophylaxis (45\% [19 of 42 women] vs. $14 \%$ [ 8 of 57 men], $p<0.001$; Table 2).

The risk of PONV in relation to the number of PONV-risk factors and the amount of PONVprophylaxis given are presented in Table 3.

\section{Cumulative PONV risk}

During the first 2 h, 9\% (CI: 5-16\%) experienced PONV with an increase to $26 \%$ (CI: 19-36\%) in the first $6 \mathrm{~h}$. At Day 1, 36\% (CI: 28-46\%) had experienced PONV, and at Day 3 46\% (CI: 37-56\%). Further details of PONV risk over time including each observation period are presented in Fig. 1 and Table 4.

\section{Factors associated with PONV-risk}

A higher incidence of PONV was observed during the first day among those who received suboptimal prophylaxis. On the third postoperative day, $70 \%$ of patients with suboptimal prophylaxis had experienced any PONV compared to $38 \%$ with optimal prophylaxis $(p<0.01$; Table 4$)$.

Being female (OR 2.33 (1.01-5.38)), having previous history of PONV (OR 5.37 (1.82-15.8)), and suboptimal 
Table 1 Patient characteristics $(n=99)$

\begin{tabular}{|c|c|}
\hline & Value \\
\hline Gender, female sex & $42(42 \%)$ \\
\hline Age, years & $67(37-87)$ \\
\hline $\mathrm{BMI}, \mathrm{m}^{2} \mathrm{~kg}^{-1}$ & $28(19-43)$ \\
\hline \multicolumn{2}{|l|}{ ASA-class } \\
\hline 1 & $26(26 \%)$ \\
\hline 2 & $60(61 \%)$ \\
\hline 3 & $13(13 \%)$ \\
\hline Smokers & $1(1 \%)$ \\
\hline History of motion sickness & 19 (19\%) \\
\hline Previous PONV & 19 (19\%) \\
\hline Preoperative treatment with opioids & $12(12 \%)$ \\
\hline COX-2 inhibitor in premedication & $9(9 \%)$ \\
\hline \multicolumn{2}{|l|}{ Apfel-score } \\
\hline $0-1$ & $0(0 \%)$ \\
\hline 2 & $44(44 \%)$ \\
\hline 3 & $35(35 \%)$ \\
\hline 4 & $20(20 \%)$ \\
\hline Hip prosthesis surgery, numbers & $78(79 \%)$ \\
\hline Knee prosthesis surgery, numbers & $21(21 \%)$ \\
\hline Spinal anaesthesia combined with intrathecal morphine and clonidine & $99(100 \%)$ \\
\hline Duration of anaesthesia, minutes & $170(105-336)$ \\
\hline Duration of surgery, minutes & $95(57-256)$ \\
\hline \multicolumn{2}{|l|}{ PONV prophylaxis } \\
\hline Betamethasone & $93(94 \%)$ \\
\hline Ondansetron & $54(55 \%)$ \\
\hline Droperidol & $20(20 \%)$ \\
\hline \multicolumn{2}{|l|}{ Number of prophylaxes given } \\
\hline 0 & $3(3 \%)$ \\
\hline 1 & $45(45 \%)$ \\
\hline 2 & $31(31 \%)$ \\
\hline 3 & $20(20 \%)$ \\
\hline Rescue antiemetics until noon Day 1 & $27(27 \%)$ \\
\hline Gabapentin included in postoperative medication & $36(36 \%)$ \\
\hline
\end{tabular}

Values are presented as numeric values (\% of total) or median (SD). ASA American Society of Anaesthesiologists Classification, PONV postoperative nausea and vomiting, $B M I$ body mass index. PONV, number of prophylaxis given: Of those receiving only 1 prophylactic drug, 42 patients received betamethasone and 3 received ondansetron. For those given two prophylaxis, all received betamethasone and ondansetron. No missing data except BMI of one patient

Table 2 Proportion of males vs. females receiving suboptimal prophylaxis

\begin{tabular}{llll}
\hline & $\begin{array}{l}\text { Men } \\
(\boldsymbol{n}=\mathbf{5 7})\end{array}$ & $\begin{array}{l}\text { Female } \\
(\boldsymbol{n}=\mathbf{4 2})\end{array}$ & p-value \\
\hline Suboptimal prophylaxis $(n=27)$ & $8(14 \%)$ & $19(45 \%)$ & \\
Optimal prophylaxis $(n=72)$ & $49(86 \%)$ & $23(55 \%)$ & $p<0.001$ \\
\hline
\end{tabular}

$p$-value for comparisons between gender and suboptimal or optimal prophylaxis with Pearson's chi-squared test
PONV prophylaxis (OR 3.04 (1.22-7.57)) had higher odds for PONV until noon Day 1 (Table 5).

\section{Discussion}

The main finding in our observational study in patients receiving intrathecal morphine was a high risk of PONV. The cumulative risk during the first three postoperative days showed that nearly half of the patients experienced 
Table 3 Risk of PONV (\%) at 0-24 h in relation to PONV risk factors and number of PONV-prophylaxis given

\section{Number of PONV-prophylaxis}

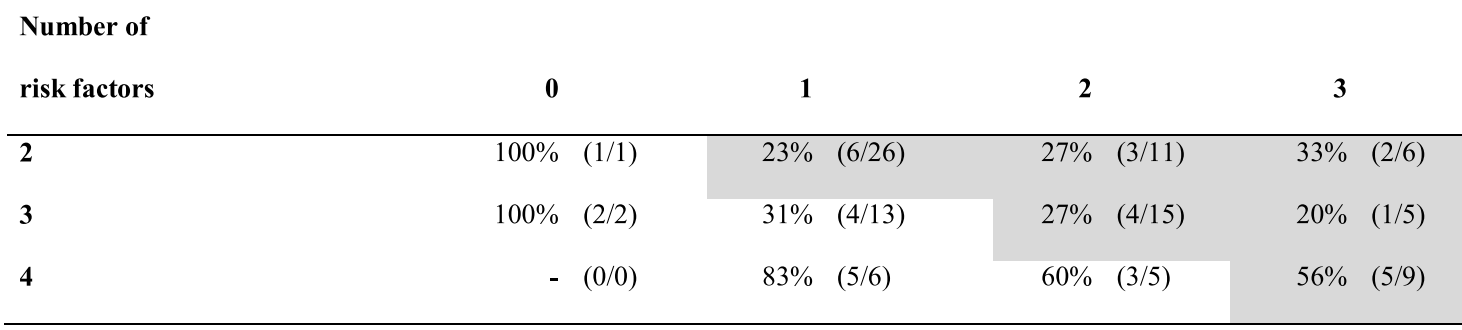

Values are risk of PONV (number of patients with PONV in subgroup / total number of patients in subgroup). Grayshaded subgroups are considered given optimal prophylaxis in accordance to the definitions in the study

PONV. Every fourth patient were given less PONVprophylaxis than the recommendations in general guidelines, and these patients had an almost doubled risk for PONV. Further, females were given less prophylaxis to a greater extent and also had a higher risk of PONV.

The PONV risk found in our cohort are in accordance with previous studies. A meta-analysis evaluating intrathecal morphine $(0.05-0.25 \mathrm{mg})$ in caesarean section found an overall PONV-risk of number needed to harm
(NNH) of 6.3 for nausea and 10.1 for vomiting [5]. Another study investigating side effects in a randomized, double-blind, dose-response study concluded that nausea was present at even low doses of intrathecal morphine $(0.015 \mathrm{mg})$ with an risk of $56 \%$ compared to a control group with a risk of $4 \%$ [6]. The absolute risks vary between studies and might be dependent on study settings and PONV prophylaxis, but many studies with intrathecal morphine report high risk for PONV [16-19].

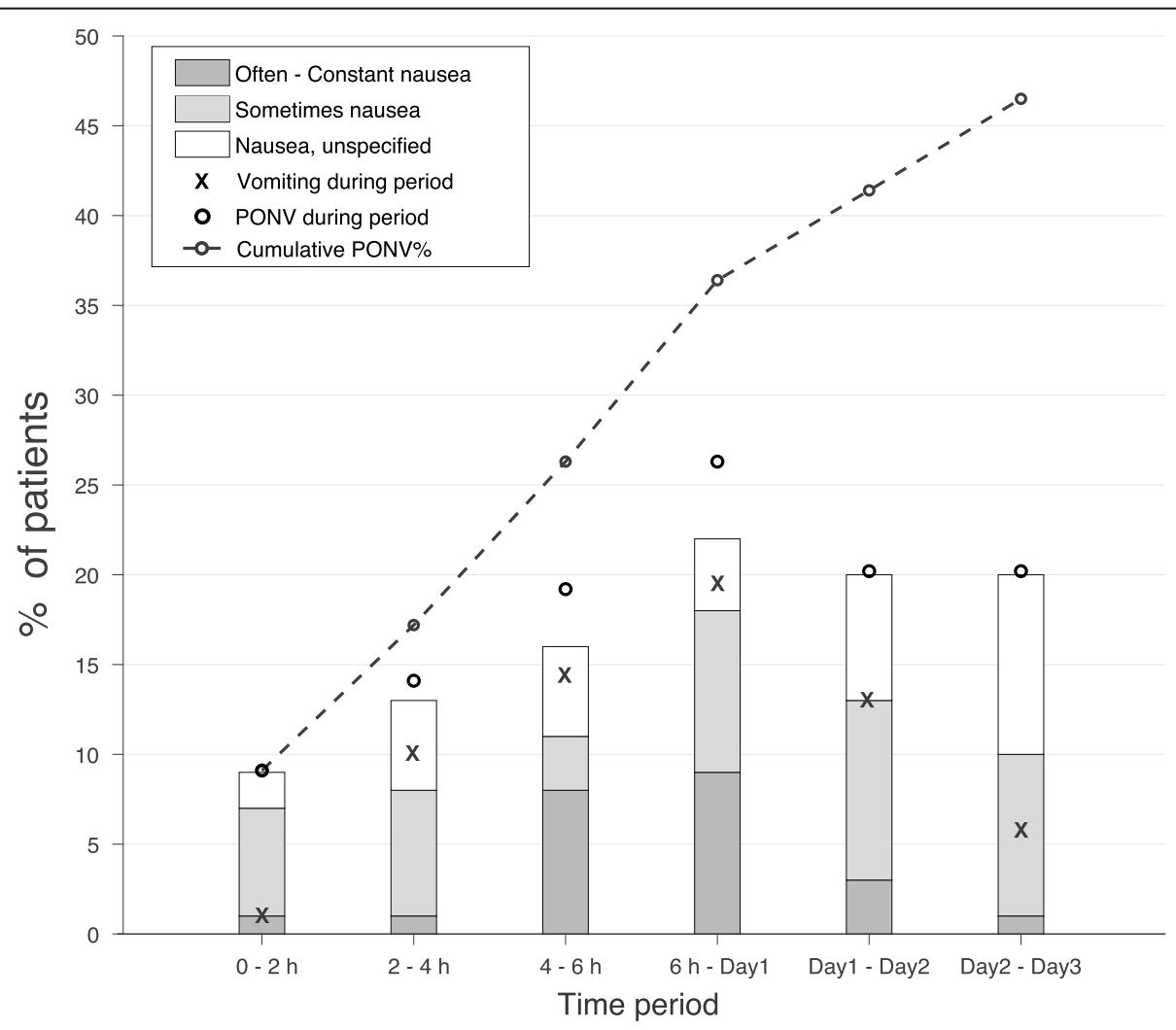

Fig. 1 Cumulative risk of PONV and risk of nausea (including frequency), vomiting, and PONV during the different observation periods. Bars represent risk for nausea, and grey parts of the bars represent nausea that affected the patient's activity (getting out of bed, moving in bed, walking normally, and eating or drinking) and was graded as sometimes (light grey) and often/constant (dark grey). The dashed line shows the cumulative incidence of PONV and accounts for the total number of patients with any event of nausea or vomiting 
Table 4 PONV risk in relation to the level of prophylaxis

\begin{tabular}{|c|c|c|c|c|}
\hline $\begin{array}{l}\text { Number of patients (\%) with } \\
\text { PONV }\end{array}$ & $\begin{array}{l}\text { All patients }(n= \\
\text { 99) }\end{array}$ & $\begin{array}{l}\text { Suboptimal PONV prophylaxis }(n= \\
\text { 27) }\end{array}$ & $\begin{array}{l}\text { Optimal PONV prophylaxis }(n= \\
\text { 72) }\end{array}$ & $p$-value \\
\hline $0 h-6 h$ & $26(26 \%)$ & $9(33 \%)$ & $17(24 \%)$ & $p=0.44$ \\
\hline 6 h-Day 1 & $26(26 \%)$ & $12(44 \%)$ & $14(19 \%)$ & $p<0.05$ \\
\hline Day 1-Day 2 & $20(20 \%)$ & $12(44 \%)$ & $8(11 \%)$ & $\begin{array}{l}p< \\
0.01\end{array}$ \\
\hline Day 2-Day 3 & $20(20 \%)$ & $8(30 \%)$ & $12(17 \%)$ & $p=0.17$ \\
\hline 0 h-Day 1 & $36(36 \%)$ & $15(56 \%)$ & $21(29 \%)$ & $\begin{array}{l}p< \\
0.05\end{array}$ \\
\hline 0 h-Day 3 & $46(46 \%)$ & 19 (70\%) & 27 (38\%) & $\begin{array}{l}p< \\
0.01\end{array}$ \\
\hline
\end{tabular}

PONV postoperative nausea and vomiting; comparison between suboptimal and optimal prophylaxis with Pearson's chi-squared test. Data collected with a standardized questionnaire answered at 2, 4 and $6 \mathrm{~h}$ after arrival at the recovery unit and at noon on postoperative days 1-3. Risk of PONV during different postoperative periods after hip or knee arthroplasty under spinal anaesthesia including intrathecal morphine. Day $1=$ first day after surgery

Almost $80 \%$ of our patients with PONV during the three-day study period presented with their first episode of PONV during the first $24 \mathrm{~h}$, indicating that there should be an awareness regarding symptoms of PONV and readiness for rescue treatments during the first postoperative day.

The third consensus guidelines from 2014 recommended that PONV-prophylaxis should be given according to individual PONV-risk and is based on the presence of PONV risk factors. With a higher risk score, the number of prophylactic interventions is increased [8]. The guideline states, that with $0,1,2,3$ or 4 risk factors, the minimum number of prophylactic agents to be $0,0,1,2,2$, respectively. We simplified the model to a linear relationship and defined optimal prophylaxis as at least $0,0,1,2,3$ agents with $0,1,2,3$, or 4 risk factors, respectively. The small differences between the models are that high-risk patients with four risk factors should be given three prophylaxis with our model, whereas the consensus guidelines recommend a minimum of two prophylaxis. As the highest risk for PONV were found in patients with four risk factors (Table 3), the results indicates that we used an acceptable model as there were differences between patients with three and four risk factors. Patients with four risk factors might be considered more prophylaxis than patients with three risk factors.

We found that almost one third of our patients were given suboptimal PONV-prophylaxis, even though there were local guidelines stating the optimal level of prophylaxis. Further, patients with suboptimal prophylaxis had an almost doubled risk for PONV. We cannot conclude if it was the suboptimal prophylaxis per se, the factors the classification was based on (i.e. female gender, previous PONV) or other unknown factors that actually caused the increased risk. Our findings agree with others that, even if guidelines are implemented in a clinical setting, there are major difficulties for clinicians to adhere to the guidelines [20]. A recent study showed that simplification of the risk assessment with a guidance to prophylaxis increased the number of patients receiving adequate PONV-prophylaxis and reduced the risk for PONV [21, 22].

We found that female gender and previous PONV were associated with a higher risk of PONV. Known risk factors for PONV are female gender, non-smoker, history of PONV or motion-sickness, and postoperative use of opioids [7]. With only one patient being a smoker and intrathecal opioids being given to all patients, it was not possible to evaluate the latter factors. Based on our findings, we suggest that factors associated with increased PONV risk after general anaesthesia might be relevant for predicting PONV risk after regional anaesthesia when intrathecal opioids are used as an adjuvant.

The use of opioids is one of the main factors that contribute to PONV [23]. All of our patients received intrathecal morphine, most of the patient's postoperative oral opioids and some rescue opioids. With our observational study design, it was not possible to evaluate the effect of each type of opioid administration. However, patients with severe pain had a tendency to a higher PONV-risk and we might speculate that this is due to an increased number of opioids given to these patients.

As our study was an observational study, we did not interfere with the treatments given to the patients. Even if there were local guidelines, patients received different postoperative analgesic and we found differences in the doses of intrathecal opioids, some patients were given Cox-2 inhibitors before the procedure and one third of the patients received oral gabapentin postoperatively. We did not find any major association to an altered risk for PONV with these factors.

Our primary outcome variable (PONV) were based on reported events of nausea and vomiting. Except reporting the frequency of PONV, we did not put the PONV 
Table 5 Factors associated with risk for PONV until noon the first postoperative day

\begin{tabular}{|c|c|c|c|c|}
\hline & $\begin{array}{l}\text { Number of } \\
\text { patients }\end{array}$ & $\begin{array}{l}\text { Number of patients } \\
\text { with PONV (\%) }\end{array}$ & $\begin{array}{l}\text { Unadjusted OR } \\
\text { (CI) }\end{array}$ & $p$-value \\
\hline \multicolumn{5}{|l|}{ Gender } \\
\hline Female & 42 & $20(48 \%)$ & $2.33(1.01-5.38)$ & 0.046 \\
\hline Male & 57 & $16(28 \%)$ & & \\
\hline \multicolumn{5}{|l|}{ BMl } \\
\hline$<35 \mathrm{~kg} / \mathrm{m}^{2}$ & 88 & $30(34 \%)$ & $1.93(0.52-7.20)$ & 0.32 \\
\hline$\geq 35 \mathrm{~kg} / \mathrm{m}^{2}$ & 10 & $5(50 \%)$ & & \\
\hline \multicolumn{5}{|l|}{ History of PONV } \\
\hline Yes & 19 & $13(68 \%)$ & $5.37(1.82-15.8)$ & 0.003 \\
\hline No & 80 & $23(29 \%)$ & & \\
\hline \multicolumn{5}{|c|}{ History of motion sickness } \\
\hline Yes & 19 & $8(42 \%)$ & $1.35(0.49-3.75)$ & 0.56 \\
\hline No & 80 & $28(35 \%)$ & & \\
\hline \multicolumn{5}{|l|}{ Non-smoker } \\
\hline Yes & 98 & $36(36 \%)$ & NA & 0.184 \\
\hline No & 1 & $1(100 \%)$ & & \\
\hline \multicolumn{5}{|c|}{ Preoperative treatment with opioids } \\
\hline Yes & 12 & $4(33 \%)$ & $0.90(0.24-3.08)$ & 0.81 \\
\hline No & 87 & $32(37 \%)$ & & \\
\hline \multicolumn{5}{|c|}{ COX-2 inhibitor in premedication } \\
\hline Yes & 9 & $3(33 \%)$ & $0.86(0.21-3.68)$ & 0.84 \\
\hline No & 90 & $33(37 \%)$ & & \\
\hline \multicolumn{5}{|c|}{ Suboptimal PONV prophylaxis } \\
\hline Yes & 27 & $15(56 \%)$ & $3.04(1.22-7.57)$ & 0.015 \\
\hline No & 72 & $21(29 \%)$ & & \\
\hline \multicolumn{5}{|c|}{ Type of prosthesis surgery } \\
\hline Hip & 78 & $27(35 \%)$ & $0.71(0.26-1.88)$ & 0.49 \\
\hline Knee & 21 & $9(43 \%)$ & & \\
\hline \multicolumn{5}{|c|}{ Intrathecal morphine, dose } \\
\hline $80-100 \mu g$ & 11 & $5(45 \%)$ & $1.51(0.42-5.42)$ & 0.79 \\
\hline $120 \mu \mathrm{g}$ & 76 & $27(35 \%)$ & reference & \\
\hline $140-200 \mu g$ & 12 & $4(33 \%)$ & $0.91(0.25-3.29)$ & \\
\hline \multicolumn{5}{|c|}{ Gabapentin given postoperatively } \\
\hline Yes & 36 & $13(39 \%)$ & $1.22(0.52-2.88)$ & 0.66 \\
\hline No & 63 & $23(35 \%)$ & & \\
\hline \multicolumn{5}{|c|}{ Given oral or parenteral opioids until noon Day 1} \\
\hline Yes & 97 & $35(36 \%)$ & $0.56(0.03-9.3)$ & 0.68 \\
\hline No & 2 & $1(50 \%)$ & & \\
\hline \multicolumn{5}{|c|}{ Maximal NRS $\geq 5$ for pain until noon Day 1 . } \\
\hline Yes & 39 & $17(44 \%)$ & $1.67(0.72-3.84)$ & 0.23 \\
\hline No & 60 & $19(32 \%)$ & & \\
\hline
\end{tabular}

Number of patients is the total number in the subgroup. PONV risk is presented as the number of patients in the subgroup with PONV (\%). Unadjusted OR, unadjusted odds ratio; Cl 95\% confidence interval, NRS Numeric Rating Scale, Day 1 first day after surgery, NA not available for calculation 
in the overall context of postoperative recovery. Today there are several validated tools to follow the postoperative quality of recovery, for example QoR-15 [24, 25], that includes several domains of recovery. Further, there are other factors, like fluid management and ambulation [26], that were not included in our study protocol and that may have impact on PONV. In future studies regarding PONV we believe it is of value to include these factors and an extensive quality of recovery tool.

A weakness in our study could be missing data, even though it was a prospective design. We might have missed PONV events that had not been identified or documented on the questionnaires, and thus the "true" result might be a higher risk for PONV. Further, there might be missed documentation of given PONV prophylaxis resulting in classification as suboptimal instead of optimal prophylaxis. This might have had an impact on the number of patients with suboptimal prophylaxis, but this would not have affected the observed high risk of PONV observed in our study.

The high risk of PONV in our study might suggest that patients undergoing hip and knee arthroplasty, including intrathecal morphine in the analgesic regime, might need more PONV prophylaxis. A main argument against a more liberal approach to PONV prophylaxis is an increased risk for side effects from the prophylactic drugs $[2,8]$. However, antiemetics are generally well tolerated [27], and the benefits from adequate prophylaxis are desirable for patients, including increased well-being and a smoother postoperative recovery. Currently there is not enough evidence to make any firm conclusions, and more clinical studies are needed to evaluate the effects of liberal PONV prophylaxis.

Recently, the fourth consensus guidelines for the management of PONV were published [12]. The major change is a more liberal approach to PONV-prophylaxis with a recommendation to give two agents to patients with 1-2 risk factors and three or four agents when more than two risk factors are present. If generalised, the new guidelines propose that patients with any risk factors for PONV should be given 1-2 additional prophylactic intervention compared to our model used in this study. Our conclusion that more prophylaxis might be needed, are in line with these new recommendations.

\section{Conclusion}

The risk for PONV after spinal morphine was high even with prophylaxis, and the increased risk was associated with known risk factors for PONV (female, previous PONV) and when a lower amount of PONV prophylaxis was given in relation to the risk. Our findings suggest that a more liberal use of PONV prophylaxis might be motivated.

\section{Abbreviations}

ASA-class: American Society of Anesthesiologists classification; BMl: Body mass index; Cl: Confidence interval; h: Hours; kg: Kilogram; mg: Milligram; $\mu \mathrm{g}$ : Microgram; NA: Not available; NNH: Number needed to harm; NRS: Numeric rating scale; OR: Odds ratio; PONV: Postoperative nausea and vomiting; QoR-15: Quality of recovery-15; SD: Standard deviation

\section{Acknowledgements \\ Not applicable.}

\section{Authors' contributions}

$\mathrm{MH}$ and JW are the main contributors to the conception and design of this study. AM is the main author working with the compilation, analysis and interpretation of the raw data and presenting it in the form of this article. AM have drafted this article with substantial revisions and feedback from $\mathrm{MH}$ and JW. JW are the main contributor to the design of the figure/tables presented in this article. All authors, ( $\mathrm{AM}, \mathrm{MH}, \mathrm{JW}$ ), have approved the submitted version and have agreed both to be personally accountable for the author's own contributions and to ensure that questions related to the accuracy or integrity of any part of the work, even ones in which the author was not personally involved, are appropriately investigated, resolved, and the resolution documented in the literature.

\section{Funding}

The study was funded by grants from Region Västernorrland and Visare Norr Fund (Northern Country Councils Regional federation). The grants were of general nature to promote scientific work in the region. The funders took no active part in this work and did not affect, influence or interfere with the study before, during or after its completion. Open access funding provided by Umea University.

\section{Availability of data and materials}

The datasets used and analysed during the current study are available from the corresponding author on reasonable request. The dataset will be edited to comply with necessary precautions to preserve individual privacy before being released.

\section{Ethics approval and consent to participate}

After obtaining written informed consent from the patients, data were collected from patient medical charts and through a standardized form with questions regarding PONV. The study was approved by the Regional Ethics Committee in Umeå, University Campus, Umeå, Sweden, on May 8, 2012 (Chairperson A. lacobaeus, Dnr 2012/146-31 M).

\section{Consent for publication \\ Not applicable.}

\section{Competing interests}

Author Jakob Walldén has received lecture fees from Abbive AB (Stockholm, Sweden).

\section{Author details}

${ }^{1}$ Department of Surgical and Perioperative Sciences, Anaesthesiology and Intensive Care Medicine (Sundsvall), Umeå University, Sundsvall, Sweden. ${ }^{2}$ Department of Surgical and Perioperative Sciences, Anaesthesiology and Intensive Care Medicine (Umeå), Umeå University, Umeå, Sweden.

Received: 2 April 2020 Accepted: 9 September 2020

Published online: 23 September 2020

\section{References}

1. Franck M, Radtke FM, Apfel CC, Kuhly R, Baumeyer A, Brandt C, et al. Documentation of post-operative nausea and vomiting in routine clinical practice. J Int Med Res. 2010;38(3):1034-41.

2. Watcha MF, White PF. Postoperative nausea and vomiting. Its etiology, treatment, and prevention. Anesthesiology. 1992;77(1):162-84.

3. Rathmell JP, Pino CA, Taylor R, Patrin T, Viani BA. Intrathecal morphine for postoperative analgesia: a randomized, controlled, dose-ranging study after hip and knee arthroplasty. Anesth Analg. 2003;97(5):1452-7.

4. Bowrey S, Hamer J, Bowler I, Symonds C, Hall JE. A comparison of 0.2 and 0 . $5 \mathrm{mg}$ intrathecal morphine for postoperative analgesia after total knee replacement. Anaesthesia. 2005;60(5):449-52. 
5. Dahl JB, Jeppesen IS, Jørgensen H, Wetterslev J, Møiniche S. Intraoperative and postoperative analgesic efficacy and adverse effects of intrathecal opioids in patients undergoing cesarean section with spinal anesthesia: a qualitative and quantitative systematic review of randomized controlled trials. Anesthesiology. 1999;91(6):1919-27.

6. Raffaeli W, Marconi G, Fanelli G, Taddei S, Borghi GB, Casati A. Opioid-related side-effects after intrathecal morphine: a prospective, randomized, doubleblind dose-response study. Eur J Anaesthesiol. 2006;23(7):605-10.

7. Apfel CC, Läärä E, Koivuranta M, Greim CA, Roewer N. A simplified risk score for predicting postoperative nausea and vomiting: conclusions from crossvalidations between two centers. Anesthesiology. 1999;91 (3):693-700.

8. Gan TJ, Diemunsch P, Habib AS, Kovac A, Kranke P, Meyer TA, et al. Consensus guidelines for the management of postoperative nausea and vomiting. Anesth Analg. 2014;118(1):85-113.

9. Kaye AD, Cornett EM, Chalabi J, Naim NZ, Novitch MB, Creel JB, et al. Pharmacology of Antiemetics: update and current considerations in anesthesia practice. Anesthesiol Clin. 2017;35(2):e41-54.

10. Kovac AL. Updates in the Management of Postoperative Nausea and Vomiting. Adv Anesth. 2018;36(1):81-97.

11. Walldén J, Flodin J, Hultin M. Validation of a prediction model for postdischarge nausea and vomiting after general anaesthesia in a cohort of Swedish ambulatory surgery patients. Eur J Anaesthesiol. 2016;33(10):743-9.

12. Gan TJ, Belani KG, Bergese S, Chung F, Diemunsch P, Habib AS, et al. Fourth consensus guidelines for the Management of Postoperative Nausea and Vomiting. Anesth Analg. 2020;131(2):411-48.

13. Wainwright TW, Gill M, McDonald DA, Middleton RG, Reed M, Sahota O, et al. Consensus statement for perioperative care in total hip replacement and total knee replacement surgery: enhanced recovery after surgery (ERAS((R))) society recommendations. Acta Orthop. 2020;91(1):3-19.

14. Myles PS, Wengritzky R. Simplified postoperative nausea and vomiting impact scale for audit and post-discharge review. Br J Anaesth. 2012;108(3):423-9.

15. Altman DG, Gardner MJSwc. Statistics with confidence: confidence intervals and statistical guidelines. In: Altman DG, et al., editors. [Great Britain]: BMJ Books. 2nd edn. London: British Medical Journal; 2000.

16. Karlsen AP, Wetterslev M, Hansen SE, Hansen MS, Mathiesen O, Dahl JB. Postoperative pain treatment after total knee arthroplasty: a systematic review. PLoS One. 2017;12(3):e0173107.

17. Hess SR, Lahaye LA, Waligora AC, Sima AP, Jiranek WA, Golladay GJ. Safety and sideeffect profile of intrathecal morphine in a diverse patient population undergoing total knee and hip arthroplasty. Eur J Orthop Surg Traumatol. 2019;29(1):125-9.

18. Pinsornsak P, Teeyaphudit M, Ruetiwarangkoon C, Chaiwuttisak A. Comparison of Ramosetron with Ondansetron for prevention of Intrathecal morphine-induced nausea and vomiting after primary Total knee Arthroplasty: a randomized control trial. J Arthroplast. 2017;32(3):1040-3.

19. Cheah JW, Sing DC, Hansen EN, Aleshi P, Vail TP. Does Intrathecal morphine in spinal anesthesia have a role in modern multimodal analgesia for primary Total joint Arthroplasty? J Arthroplast. 2018;33(6):1693-8.

20. Kranke $P$, Eberhart LH. Possibilities and limitations in the pharmacological management of postoperative nausea and vomiting. Eur J Anaesthesiol. 2011;28(11):758-65.

21. Dewinter G, Staelens W, Veef E, Teunkens A, Van de Velde M, Rex S. Simplified algorithm for the prevention of postoperative nausea and vomiting: a before-and-after study. $\mathrm{Br} J$ Anaesth. 2018;120(1):156-63.

22. Kappen TH. Risk-tailored prophylaxis for postoperative nausea and vomiting: has the big little problem gotten any smaller? Br J Anaesth. 2018;120(1):9-13.

23. Hom CC, Wallisch WJ, Homanics GE, Williams JP. Pathophysiological and neurochemical mechanisms of postoperative nausea and vomiting. Eur J Pharmacol. 2014;722:55-66.

24. Lyckner S, Boregard IL, Zetterlund EL, Chew MS. Validation of the Swedish version of quality of recovery score -15 : a multicentre, cohort study. Acta Anaesthesiol Scand. 2018;62(7):893-902.

25. Stark PA, Myles PS, Burke JA. Development and psychometric evaluation of a postoperative quality of recovery score: the QoR-15. Anesthesiology. 2013;118(6):1332-40.

26. Jewer JK, Wong MJ, Bird SJ, Habib AS, Parker R, George RB. Supplemental perioperative intravenous crystalloids for postoperative nausea and vomiting. Cochrane Database Syst Rev. 2019;3:CD012212.

27. De Hert S, Staender S, Fritsch G, Hinkelbein J, Afshari A, Bettelli G, et al. Preoperative evaluation of adults undergoing elective noncardiac surgery: updated guideline from the European Society of Anaesthesiology. Eur J Anaesthesiol. 2018;35(6):407-65.

\section{Publisher's Note}

Springer Nature remains neutral with regard to jurisdictional claims in published maps and institutional affiliations.

\section{Ready to submit your research? Choose BMC and benefit from:}

- fast, convenient online submission

- thorough peer review by experienced researchers in your field

- rapid publication on acceptance

- support for research data, including large and complex data types

- gold Open Access which fosters wider collaboration and increased citations

- maximum visibility for your research: over $100 \mathrm{M}$ website views per year

At BMC, research is always in progress.

Learn more biomedcentral.com/submissions 